\title{
Nutritional potential of malted nutri flour against conventional flours used in Indian food products
}

\author{
Jaya Tripathi* \\ *Department of Food, Nutrition and Public Health, Sam Higginbottom University of Agri- \\ culture, Technology and Sciences, Allahabad (Uttar Pradesh), India \\ Janardan Singh \\ Udaipur Beverages Pvt. Ltd., Jabalpur (Madhya Pradesh), India \\ ${ }^{*}$ Corresponding author. E-mail: jayatripathi1009@gmail.com

\section{Abstract}

The purpose of this study was to introduce nutri flour in the development of value-added food products. Nutri flour was developed using malted wheat, malted barnyard millet and malted pearl millet. The proximate composition, iron, some anti-nutritional factors (oxalates, phytates) and antioxidant activity were determined for developed nutri flour and conventional flours like whole wheat flour, refined wheat flour and Bengal gram flour. The results indicated that the developed nutri flour had the highest protein $(18.68 \mathrm{~g} / 100 \mathrm{~g})$ as well iron content $(9.22 \mathrm{mg} / 100 \mathrm{~g})$ which was significantly higher than other conventional flours. The nutritional quality of the obtained nutri flour suggests that the flour can be considered as an alternative to conventional existing flours in process of food product development ensuring better nutritional quality of developed products.
\end{abstract}

Keywords: Barnyard millet, Conventional flours, Food product development, Nutri flour, Pearl millet.

\section{INTRODUCTION}

Nowadays millets are considered as potential replacement for staple crops to tackle with the scarcity of Food. Millets have exceptional nutritional composition as compared with other cereals. In the present existing situation of the society, there is need to exploit the positive nutritional benefits of millets and to popularize them among all for achieving nutritional and food security. Among all the millets, Pearl millet (Pennisetum glaucum) is the most drought-tolerant and can be grown in typically dried areas too. Nutritionally pearl millet contains iron, zinc, qualitative and balanced proteins (Elyas et al. 2002) and diverse health promoting phenolic compounds. Because of its health benefitting properties, it is being used in functional food preparations (Dykes and Roony, 2006). Pearl millet is particularly rich in iron and zinc and antioxidants which altogether may prove beneficial for treating deficiency diseases like anaemia. Barnyard millet (Echinochloa frumantacea) is important millet having ample amount of protein coupled with carbohydrate content. Barnyard millet is an excellent source of micronutrients especially iron. Along with that, this millet has great potential to blend with other cereals without giving any off flavour and aftertaste. Thus this millet can be added in traditional food preparations to add value in peculiar food uses (Veena, 2003). Food based approaches are gaining high potential for long lasting benefits in improving iron status. Fortification of a food lacking in iron with a iron dense food is an effective strategy. For effective food fortification, the fortified food consumed by the consumers must be cost effective as well as acceptable on sensory parameters. The process of selecting the best food vehicle and iron source may appear simple but is actually a complex process that requires evaluation at every step. Thus, the present study is a step to examine the potential of nutri flour as an alternative to conventional flours used in Indian food preparations.

\section{METHODOLOGY}

Materials: For the experiments, millets (Pearl millet and Barnyard millet) and wheat produced in Allahabad area were purchased through local market of Allahabad, India, soon after harvest. Conventional flours like whole wheat flour, refined wheat flour and Bengal gram flour were also purchased from the market.

Development of Nutri-flour: Selected grains were soaked and germinated to increase micronutrient content and to decrease anti-nutritional factors present. Following time and temperature combination was used for malting; 16 hours of soaking period at a germination temperature $\left(31^{\circ} \mathrm{C}\right)$ and 
germination period (48 hours) (Tripathi et al. 2013) followed by drying of grains in hot air oven at $50^{\circ} \mathrm{C}$ for 24 hours and finally grinding. The nutri flour was developed from malted barnyard millet, malted pearl millet and malted wheat flour by mixing these three flours in different proportions (Malted wheat flour 40g: malted pearl millet flour $30 \mathrm{~g}$ : malted barnyard millet flour $30 \mathrm{~g}$ ) after random trials based on kneading properties.

Nutritional analysis: The proximate compositions were determined in accordance with the standard methods of the (AOAC, 2007). Calories were obtained by the addition of multiplied mean values for protein, fat and carbohydrates by their respective calculation factors, 4,9 , and 4 . Calcium was determined using visible titration method and iron was determined using colorimetric method (AOAC,2007).

Antioxidant analysis: Total polyphones were estimated as per procedure described by Singleton et al. (1999) using Folin ciocalteu method. The antioxidant activity of native and processed ingredients was also measured by the DPPH radical scavenging method (De Ancos, Sgroppo, Plaza, \& Cano, 2002).

Anti-nutritional factors analysis: Phytate was determined using the method as prescribed by Sadasivam \& Manickam (2009). Oxalate was determined according to the method by Day and Underwood (1986).

Statistical analysis: All experiments were carried out in triplicates for the analysis of each nutrient. The mean and standard deviation for each the nutrient analysed were calculated and recorded. For comparison among all the flours, randomized block design ANOVA test was used and critical difference was applied to check significant difference.

\section{RESULTS}

The data in respect to comparison of developed malted nutri-flour with common flours like whole wheat flour, refined wheat flour and Bengal gram flour is presented inTable 1.

Moisture content was found highest in malted nutri flour (MNF) i.e. 13.66 \pm 0.08 grams followed by whole wheat flour (WWF) i.e. $12.37 \pm 0.09 \mathrm{~g}$, refined wheat flour (RWF) i.e. $4.26 \pm 0.06 \mathrm{~g}$ and least in Bengal gram flour (BGF) i.e. $3.90 \pm 0.15 \mathrm{~g}$. Significant differences ( $p>0.05$ ) were found between moisture content of malted nutri flour (MNF) and Bengal gram flour (BGF). As far as protein composition was concerned, the data revealed that malted nutri flour has the highest protein content i.e. $18.68 \pm 0.09 \mathrm{~g}$ followed by Bengal gram flour i.e. $15.28 \pm 0.08 \mathrm{~g}$, whole wheat flour i.e. $12.63 \pm 0.04 \mathrm{~g}$ and least in refined wheat flour i.e. $9.18 \pm 0.31 \mathrm{~g}$. Significant differences $(p>0.05)$ were found between protein content of malted nutri flour (MNF) and refined wheat flour (RWF). Fat content was found to be highest in malted nutri flour (MNF) i.e. $4.31 \pm 0.04 \mathrm{~g}$, followed by Bengal gram flour i.e. $4.12 \pm 0.14 \mathrm{~g}$, whole wheat flour i.e. $1.39 \pm 0.03$ and least in refined wheat flour i.e. $0.69 \pm 0.01 \mathrm{~g}$. Significant differences $(p>0.05)$ were found between fat content of malted nutri flour (MNF) and refined wheat flour (RWF). Fibre content was again found highest in malted nutri flour i.e. $7.28 \pm 0.05 \mathrm{~g}$ followed by Bengal gram flour i.e. $2.90 \pm 0.02$, whole wheat flour i.e. $1.61 \pm 0.13$ and least in refined wheat flour i.e. $0.17 \pm 0.04 \mathrm{~g}$. Significant differences $(p>0.05)$ were found between fibre content of malted nutri flour (MNF) and refined wheat flour (RWF). Ash content among all the flour was found to be highest in malted nutri flour i.e. $2.98 \pm 0.03 \mathrm{~g}$, followed by whole wheat flour i.e. $1.63 \pm 0.04 \mathrm{~g}$, Bengal gram flour i.e. $1.47 \pm 0.10 \mathrm{~g}$ and least in refined wheat flour i.e. $0.91 \pm 0.07 \mathrm{~g}$.

Highest carbohydrate content was found in refined wheat flour i.e. $84.94 \pm 0.30 \mathrm{~g}$ followed by Bengal gram flour i.e. $75.22 \pm 0.04 \mathrm{~g}$, whole wheat flour i.e. $71.97 \pm 0.03 \mathrm{~g}$ and least in malted nutri flour i.e. $60.35 \pm 0.14 \mathrm{~g}$. Energy content was recorded highest in Bengal gram flour i.e. $399.09 \pm 1.01 \mathrm{Kcal}$ followed by refined wheat flour i.e. $382.77 \pm 0.13$ Kcal, malted nutri flour i.e. $354.96 \pm 0.41 \mathrm{Kcal}$ and least in whole wheat flour i.e. $350.98 \pm 0.47$.

In case on minerals, again developed malted nutri flour has found to have highest iron content i.e. $9.22 \pm 0.10 \mathrm{mg} / 100 \mathrm{~g}$ followed by whole wheat flour i.e. $5.12 \pm 0.04 \mathrm{mg} / 100 \mathrm{~g}$, Bengal gram flour i.e. $4.51 \pm 0.07 \mathrm{mg} / 100 \mathrm{~g}$ and least in refined wheat flour i.e. $2.55 \pm 0.11 \mathrm{mg} / 100 \mathrm{~g}$. Calcium content was significantly found to be highest in Bengal gram flour i.e. $191.84 \pm 3.31 \mathrm{mg} / 100 \mathrm{~g}$ followed by whole wheat flour i.e. $50.95 \pm 0.41 \mathrm{mg} / 100 \mathrm{~g}$, malted nutri flour i.e. $27.08 \pm 0.18 \mathrm{mg} / 100 \mathrm{~g}$ and least in refined wheat flour i.e. $26.60 \pm 1.86 \mathrm{mg} / 100 \mathrm{~g}$.

Total phenolic content was found highest in Bengal gram flour i.e. $251.80 \pm 0.42 \mathrm{mg} / 100 \mathrm{f}$ followed by refined wheat flour i.e. $178.90 \pm 0.43 \mathrm{mg} / 100 \mathrm{~g}$, malted nutri flour i.e. $68.11 \pm 0.29 \mathrm{mg} / 100 \mathrm{~g}$ and least in whole wheat flour i.e. $36.59 \pm 0.81$ $\mathrm{mg} / 100 \mathrm{~g}$. DPPH Radical scavenging activity of malted nutri flour was recorded highest i.e. $77.41 \pm 0.12$ per cent followed by whole wheat flour i.e. $33.96 \pm 0.40$ per cent, Bengal gram flour i.e. $23.61 \pm 0.29$ per cent and least in refined wheat flour i.e. $12.86 \pm 0.42$.

The phytate content was recorded highest in whole wheat flour i.e. $239.22 \pm 0.49 \mathrm{mg} / 100 \mathrm{~g}$, followed by malted nutri flour i.e. 236.86 \pm 0.21 $\mathrm{mg} / 100 \mathrm{~g}$, Bengal gram flour i.e. $133.09 \pm 0.12 \mathrm{mg} / 100 \mathrm{~g}$ and least in refined wheat flour i.e. $121.44 \pm 0.69 \mathrm{mg} / 100 \mathrm{~g}$. As far as oxalate content was concerned, it was found to be highest in malted nutri flour i.e. $14.63 \pm 0.08 \mathrm{mg} / 100 \mathrm{~g}$ followed by whole wheat flour i.e. 13.33 \pm 0.67 $\mathrm{mg} / 100 \mathrm{~g}$, refined wheat flour i.e. $6.21 \pm 0.24$ 
Tripathi, J. and Singh, J. / J. Appl. \& Nat. Sci. 11(3): 694 - 697 (2019)

Table 1. Comparison of malted Nutri flour with common flours used in conventional Indian products.

\begin{tabular}{llllll}
\hline & MNF & WWF & RWF & BGF & CD (p>0.05) \\
\hline Moisture (g) & $13.66 \pm 0.08^{*}$ & $12.37 \pm 0.09$ & $4.26 \pm 0.06$ & $3.90 \pm 0.15^{*}$ & 9.77 \\
Protein (g) & $18.68 \pm 0.09^{*}$ & $12.63 \pm 0.04$ & $9.18 \pm 0.31^{*}$ & $15.28 \pm 0.08$ & 7.60 \\
Fat $(\mathrm{g})$ & $4.31 \pm 0.04^{*}$ & $1.39 \pm 0.03$ & $0.69 \pm 0.01^{*}$ & $4.12 \pm 0.14$ & 3.50 \\
Fibre (g) & $7.28 \pm 0.05^{*}$ & $1.61 \pm 0.13$ & $0.17 \pm 0.04^{*}$ & $2.90 \pm 0.02$ & 5.78 \\
Ash (g) & $2.98 \pm 0.03^{*}$ & $1.63 \pm 0.04$ & $0.91 \pm 0.07^{*}$ & $1.47 \pm 0.10$ & 1.67 \\
Carbohydrates (g) & $60.35 \pm 0.14^{*}$ & $71.97 \pm 0.03$ & $84.94 \pm 0.30^{*}$ & $75.22 \pm 0.04$ & 19.10 \\
Energy (Kcal) & $354.96 \pm 0.41^{*}$ & $350.98 \pm 0.47^{* *}$ & $382.77 \pm 0.13$ & $399.09 \pm 1.01^{* * * *}$ & 43.29 \\
Iron (mg) & $9.22 \pm 0.10^{*}$ & $5.12 \pm 0.04$ & $2.55 \pm 0.11^{*}$ & $4.51 \pm 0.07$ & 5.28 \\
Calcium (mg) & $27.08 \pm 0.18^{*}$ & $50.95 \pm 0.41$ & $26.60 \pm 1.86^{* *}$ & $191.84 \pm 3.31^{* * * *}$ & 149.47 \\
TPC (mg/100g ) & $68.11 \pm 0.29$ & $36.59 \pm 0.81^{*}$ & $178.90 \pm 0.43$ & $251.80 \pm 0.42^{*}$ & 187.41 \\
DPPH \% & $77.41 \pm 0.12^{* * * *}$ & $33.96 \pm 0.40$ & $12.86 \pm 0.42^{*}$ & $23.61 \pm 0.29^{* *}$ & 53.31 \\
Phytates (mg) & $236.86 \pm 0.21$ & $239.22 \pm 0.49$ & $121.44 \pm 0.69$ & $133.09 \pm 0.12$ & 120.77 \\
Oxalates (mg) & $14.63 \pm 0.08^{*}$ & $13.33 \pm 0.67$ & $6.21 \pm 0.24$ & $4.03 \pm 0.05^{*}$ & 9.92 \\
\hline
\end{tabular}

$* * *$ Values in Parenthesis indicate significant differences; Values are mean \pm SE of three independent determination. MNF - Malted Nutri Flour WWF - Whole Wheat Flour, RWF - Refined Wheat Flour, BGF - Bengal Gram Flour

$\mathrm{mg} / 100 \mathrm{~g}$ and least in Bengal gram flour i.e. $4.03 \pm 0.05 \mathrm{mg} / 100 \mathrm{~g}$.

A glance at the data reveals that malted nutri flour developed from malted wheat flour, malted pearl millet flour and malted barnyard millet flour in present study has richer and denser nutritional composition as compared with the common flours used in traditional Indian preparations. Malting has proved to be very influential in enhancing nutritional and mineral composition of flour developed. To bring back the millets in consumption pattern of individuals, development of various value-added products replacing common flours with composite flour may serve good vehicle for carrying the added nutrient to the target population. Several researches have reported the successful replacement of traditional flours with formulated composite flours of cereals, millets and pulses in traditional preparations and found them nutritionally superior than conventional products (Anu et al. 2008, Desai et al. 2010 and Jain 2012).

Nazni and Devi (2016) also studied about effect of processing (Germination, Boling, Roasting and Pressure Cooking) on nutritional and antinutritional contents of barnyard millet and foxtail millet. Results revealed that here was a significant variation with respect to functional, nutritional, anti -nutritional and pasting properties of selected two millets in response to different processing methods. Among them, germination reduces the antinutritional factors while roasting significantly increases the nutritional compounds. Iron content of barnyard millet was mostly affected by pressure cooking i.e. $8.9 \mathrm{mg} / 100 \mathrm{~g}$ followed by germination i.e. $7.59 \mathrm{mg} / 100 \mathrm{~g}$. Chouhan et al., (2016) too analysed the impact of processing methods on barnyard millet flour. Processing methods applied to millet flour were soaking, germination, roasting and proximate, phytochemical and anti-nutrient analysis were analysed. The results revealed that protein content slightly decreased after processing only germinated flour protein content was in- creased $(5.4 \mathrm{~g})$. Fat content of the barnyard millet was decreased after processing but the roasted barnyard millet flour was found to be increased fat $(3.4 \mathrm{~g})$. Calcium and iron content were increased after germination i.e. calcium $(20.2 \mathrm{mg} / 100 \mathrm{~g})$ and iron $(14.4 \mathrm{mg} / 100 \mathrm{~g})$. Anti-nutrient content was decreased after processing.

Again, in a study, Obadina et al., (2016) investigated the effect of roasting on nutritional composition of pearl millet flour. Sample roasted at $180^{\circ} \mathrm{C}$ for 10 minutes had the highest iron content i.e. $452.56 \mathrm{mg} / 100 \mathrm{~g}$. Roasting increased the water solubility index and oil absorption capacity of the flour samples. An increase in roasting temperature led to a significant decrease in the phenolic content of the samples. Roasting reduced some of the nutrients of the pearl millet flours and increased their functional properties. Gautam et al., (2015) also studied about impact of malting on nutritional composition of foxtail millet, wheat and chickpea. The data revealed that Protein, Fibre, Vitamin C and Iron content was found to be increased in malted foxtail millet flour i.e. $11.6 \mathrm{~g}, 13.04 \mathrm{~g}, 70$ $\mathrm{mg} / 100 \mathrm{~g}$ and $26.82 \mathrm{mg} / 100 \mathrm{~g}$ respectively. The results suggested that malting can be used as effective processing method to enhance nutritional component of grains.

Suma and Urooj (2014) too examined the impact of germination on nutritional composition of pearl millet. Results indicated that bio-accessible iron and calcium were considerable enhanced after germination which was attributed to reduction of anti-nutrients. The iron content was increased from native to proceeds millet i.e. from $5.0 \mathrm{mg} / 100 \mathrm{~g}$ to $8.9 \mathrm{mg} / 100 \mathrm{~g}$. The calcium content was also increased i.e. from $41.3 \mathrm{mg} / 100 \mathrm{~g}$ to $49.1 \mathrm{mg} / 100 \mathrm{~g}$.

\section{Conclusion}

Therefore, it has been concluded that malted nutri flour developed from malted wheat flour, malted pearl millet flour and malted barnyard millet flour in present study has richer and denser nutritional 
composition as compared with the common flours used in traditional Indian preparations. The malted nutri flour has a protein content of $18.68 \mathrm{~g} / 100 \mathrm{~g}$ and an excellent iron content of $9.22 \mathrm{mg} / 100 \mathrm{~g}$. The use of nutri flour may bring the promotion of high-yielding native plant species, a better supply of protein and iron for human nutrition and a better overall use of domestic agriculture production.

\section{ACKNOWLEDGEMENTS}

The authors are grateful to University Grants Commission (UGC), New Delhi for providing fellowship to conduct this study.

\section{REFERENCES}

1. AOAC. (2007). Official methods of analysis 18th edition. Association of official Analytical Chemists, Washington, DC

2. Anu, Sehgal S. and Kawatra. A. (2008). Development and nutritional evaluation of pearl millet rich banana cake. Journal of Dairying, Foods and Home Sciences, 27 (2): 138 - 141

3. Chouhan, E.S., Yadav, S. and Negi, N. (2016). Proximate, phytochemical and antinutrient analysis of unprocessed and processed barnyard millet flours. International Ayurvedic Medical Journal, [e-journal], 2482-2487

4. Day, J.R.A. and Underwood A.L. (1986) Quantitative Analysis. $5^{\text {th }}$ Edition. Prentice Hall Publication, Eaglewood Cliffs. Pp 710

5. De Ancos, B., Sgroppo, S., Plaza, L. and Cano, M. P. (2002). Possible nutritional and health-related value promotion in orange juice preserved by highpressure treatment. Journal of the Science of Food and Agriculture, 82, 790-796

6. Desai, D. A., Kulkarni, S.S., Sahoo, A.K., Ranveer, R.C. and Dandge, P.B. (2010). Effect of supplementation of malted ragi flour on the nutritional and sensory quality characteristics of cake. Advanced Journal of Food. Science and Technology, 2 (1): 67-71

7. Dykes, L. and Rooney, L.W. (2006). Sorghum and millet phenols and antioxidants. Journal of Cereal Science, 44:236-251

8. Elyas, S. H., El-Tinay, A. H., Yosif, N.E. and Elsheikh, E.A. (2002). Effect of fermentation on nutritive value and in vitro protein digestibility of pearl millet. Food Chemistry, 78: 75-79

9. Gautam, L., Chaturvedi, N. and Srivastava, R. (2015). Impact of Malting on Nutritional Composition of Foxtail Millet, Wheat and Chickpea. Journal of Nutrition and Food Sciences, 5:5, http:/l dx.doi.org/10.4172/2155-9600.1000407

10.Jain, A. (2012). Utilization of amaranth for the preparation of value added ready-to-eat extruded snacks. M.Sc. Thesis, CCSHAU, Hisar

11.Nazni, P. and Devi, S.R. (2016). Effect of Processing on the Characteristics Changes in Barnyard and Foxtail Millet. Journal of Food Processing and Technology, 7:566. doi:10.4172/2157-7110.1000566

12. Obadina, O.A., Isaac, O.I., Ifeoluwa, O.A., Antonio, G.S., Carlos, W.P.C. and Henriqueta, T.B. (2016). Nutritional and Physicochemical properties of flour from native and roasted whole grain pearl millet (Pennisetum glaucum [L.]R. Br.). Journal of Cereal Science.70:247-252

13.Sadasivam, S. and Manickam, A. (1996). Biochemical methods. 2nd edition, New Age International (p) Ltd. Publisher, New Delhi, pp 179-186

14.Singleton, V.L., Orthofer, R., Lamuela-Raventos, R.M. (1999). Analysis of total phenols and other oxidation substrates and antioxidants by means of FolinCiocalteu reagent. Methods Enzymol., 299:152-178

15.Suma, P.F. and Urooj, A. (2014). Influence of germination on bioaccessible iron and calcium in pearl millet (Pennisetum typhoideum). Journal of Food Science and Technology, 51(5): 976-981

16.Veena, B. (2003). Nutritional, functional and utilization studies on barnyard millet. M.Sc. Thesis, University of Agricultural Sciences, Dharwad, India

17. Tripathi J. (2013). Utilization of Malting for Development of Value Added Products from Selected Millets. M.Sc. Thesis. University of Allahabad, Allahabad, India 